\title{
OS DESAFIOS DO PEDAGOGO NA FUNÇÃO SUPERVISORA EM UMA INSTITUIÇÃO DE EDUCAÇÃO PROFISSIONAL
}

\author{
I. A. CARVALHO \\ Instituto Federal do Amapá - IFAP \\ isabella.carvalho@ifap.edu.br
}

Artigo submetido em fevereiro/2014 e aceito em março/2014

\section{RESUMO}

O objetivo deste artigo é possibilitar a compreensão sobre os desafios postos ao trabalho do pedagogo na função supervisora de uma instituição de educação profissional, mas especificamente no Instituto Federal de Educação, Ciência e Tecnologia do Amapá que faz parte da Rede Federal de Educação Profissional, Científica e Tecnológica. Este trabalho em sua organização inicial faz um breve estudo sobre a formação e papel do pedagogo no Brasil, focalizando a sua função enquanto supervisor escolar, contextualizando as mudanças e o seu perfil. Em seguida, aborda o espaço da educação profissional, a fim de verificar as competências, a relação com os professores, a percepção que estes têm do trabalho do pedagogo e os desafios de sua gestão pedagógica nesse espaço. Para essa investigação, se fez necessário enfoque na pesquisa qualitativa que se caracteriza por buscar compreender e classificar um determinado fenômeno social. Foram aplicadas entrevistas com o corpo docente, que no cotidiano da escola, mais interações possui com o pedagogo, e também com estes.

PALAVRAS-CHAVE: Supervisão escolar; Desafios; Educação Profissional; Relação pedagogo-professor.

\section{THE CHALLENGES OF THE SUPERVISORY FUNCTION PEDAGOGUE INSTITUTION IN A PROFESSIONAL EDUCATION}

\begin{abstract}
The purpose of this article is to enable understanding of the challenges posed to the work of the pedagogue in supervisory function of an institution of professional education, but specifically at the Federal Institute of Education, Science and Technology of Amapá part of the Federal Network of Vocational Education, Scientific and Technology. This work in its initial organization makes a brief study of the formation and role of the educator in Brazil, focusing on its role as a school supervisor, contextualizing the changes and your profile. It then
\end{abstract}

addresses the space of vocational education in order to verify the skills, relationship with teachers, the perception that these are the work of the pedagogue and the challenges of their educational management in this space. For this research, it was necessary to focus on qualitative research that is characterized by seeking to understand and classify a particular social phenomenon Interviews with faculty who daily at school, has more interactions with the teacher, and these were also applied .

KEYWORDS: School supervision; Challenges; Vocational Education; pedagogue-teacher ratio. 


\section{INTRODUÇÃO}

Situando de modo mais específico a atuação do pedagogo na função supervisora, convém destacar que a escolha dessa temática, deu-se por considerá-la desafiadora para o pedagogo, em especial nas Instituições de Educação Profissional, uma vez que o papel do pedagogo na educação profissional ainda é pouco debatido, tanto na literatura da área, quanto nas discussões nacionais a respeito da identidade deste profissional. Entretanto, não se pode desconhecer que competências e habilidades mais amplas passam a ser exigidas desse profissional, a fim de que tenha condições de responder efetivamente às tarefas e desafios dentro dos processos educativos.

Nessa perspectiva, o presente estudo tem como objetivo identificar os desafios postos ao pedagogo na função supervisora no espaço de uma instituição de educação profissional. Para atender esse objetivo, faz-se necessário: realizar um breve estudo acerca da formação do pedagogo no Brasil; contextualizar historicamente a supervisão; destacar as competências e desafios do pedagogo na função supervisora nesse espaço; identificar a percepção dos professores acerca da atuação do Pedagogo-Supervisor como organizador de seu espaço de aprendizagem dentro da escola; verificar a relação estabelecida entre Pedagogo-Supervisor e professor e as consequências no desenvolvimento do trabalho escolar; e também analisar a concepção dos pedagogos que trabalham como articuladores das questões didático-pedagógicas e administrativas nesta modalidade de ensino.

Visando proporcionar maior aproximação da realidade estudada, foram utilizados como instrumentos, a entrevista semi-estruturada aplicada a um universo de 13 (treze) sujeitos, constituindo-se de cinco professores da formação geral, cinco professores da parte profissional e três pedagogas. A escolha por uma Instituição de Educação Profissional deu-se por ter surgido a necessidade de sistematizar questionamentos e reflexões que surgem ao longo do trabalho pedagógico e das experiências nesta modalidade de educação, em especial com o corpo docente, por ser este um dos públicos que, no cotidiano escolar, mais interfaces possui com o pedagogo.

Os roteiros de entrevistas estão compostos de 05 questões, aplicadas aos professores (as) e de 06 questões, aplicadas aos pedagogos (as). Todas as questões foram analisadas, mas pelo fato de algumas se complementarem foram incorporadas, compondo uma única questão.

O presente trabalho se encontra estruturado da seguinte forma: inicialmente realiza-se breves colocações sobre a formação do pedagogo no Brasil para em seguida focalizar a sua função enquanto supervisor escolar, contextualizando as mudanças e o perfil do pedagogo da década de 60 à atualidade. Num segundo momento, parte-se mais profundamente para um estudo das competências, relação com os professores, a percepção que eles têm do trabalho do pedagogo e os desafios de sua gestão pedagógica no espaço da educação profissional.

Por fim, confrontando os dados obtidos com os sujeitos entrevistados e os estudos teóricos relacionados a esta área, apresentam-se alguns apontamentos e considerações sobre os desafios e problemáticas do pedagogo na função supervisora. 


\section{CONTEXTUALIZANDO A FORMAÇÃO DO PEDAGOGO E SUPERVISÃO ESCOLAR}

A pedagogia ocupa-se do estudo sistemático da educação e na trajetória histórica sobre a educação e formação do pedagogo no Brasil, muitos dilemas e impasses em torno da identidade do pedagogo e do curso foram marcantes, até se chegar ao seguinte entendimento quanto à formação de pedagogos:

O curso de Pedagogia deve formar o pedagogo stricto sensu, isto é, um profissional qualificado para atuar em vários campos educativos para atender demandas sócio-educativas de tipo formal e não-formal e informal, decorrentes de novas realidades [...] etc (LIBÂNEO, 2007, p.38).

Ou seja, o campo de atuação do profissional formado em pedagogia é tão vasto quanto são as práticas educativas na sociedade. Mas em especial, essa pesquisa dá destaque ao pedagogo escolar, que historicamente teve papel marcado, em sua formação e atuação, pela fragmentação em diversas habilitações, entre elas as de supervisor, orientador, inspetor e administrador (Parecer CFE 252/1969).

Apesar de que no contexto atual, desde a reformulação do curso de Pedagogia com as Diretrizes Curriculares Nacionais (Resolução CNE/CP n. 1, de 15 de maio de 2006), não haver mais a formação do pedagogo com base em habilitações específicas e sim a formação do pedagogo unitário, ainda hoje a atuação do pedagogo escolar continua tendo por base práticas centradas nas funções supervisora e orientadora.

No que se refere à supervisão escolar, sabe-se que este trabalho surgiu com a industrialização, onde se visava o aprimoramento dos aspectos qualitativos e quantitativos da produção. Posteriormente, esse trabalho foi incorporado pelo sistema educacional, a fim de que a escola passasse a ser mais produtiva, assim como ocorria na indústria. Desta forma, a figura do supervisor nos espaços das fábricas durante o século XVIII e princípio do século XIX se define como função de inspecionar, reprimir, checar e monitorar as ações dos trabalhadores, numa relação autoritária e de reprodução.

Segundo Medina (2002, p.46), o perfil de supervisão passa a apresentar mudanças no final do século XIX e início do século XX, especialmente nas décadas de 70 e 90, época em que a supervisão escolar estava vivendo uma fase de transição, tendo em vista que almejava passar de simples inspeção para um trabalho cooperativo e democrático.

A sociedade e a escola começam a ser questionadas e autores como Freire (1972), Saviani (1973), dentre outros, começam a assinalar um movimento novo a respeito da escola e de seu papel na sociedade global. Nesse contexto, se fortalece a discussão sobre uma pedagogia comprometida com os interesses da maioria da população, as classes trabalhadoras, gerando, consequentemente um novo entendimento a respeito de qual deve ser o papel do pedagogo escolar. O pedagogo escolar, enquanto supervisor passa de uma função controladora, fiscalizadora, individualista e burocratizada para uma função de acompanhamento, apoio e suporte pedagógico tendo como foco a organização coletiva do trabalho escolar.

No contexto atual, não cabe mais visualizar o pedagogo supervisor como um profissional que se sobrepõe aos professores, numa condição de hierarquia, fundamentada na ideia de que é ele quem comanda, define e determina o trabalho a ser realizado. Agora se torna necessária a 
compreensão de que o apoio e a solidariedade mútua entre o pedagogo supervisor e professores é possível com uma supervisão compartilhada.

De acordo com Falcão Filho (1994), a supervisão compartilhada possui três pressupostos que precisam ser considerados: 1) A ação supervisora deve ser desenvolvida com os professores e não para os professores; 2) O professor e o supervisor são partes indissoluvelmente ligadas e de igual importância no processo educativo; 3) O supervisor e o professor estão num mesmo nível hierárquico, consequentemente o professor não é um subordinado do professor, e nem tampouco o supervisor é seu supervisor hierárquico.

Sendo assim, percebe-se que o pedagogo supervisor torna-se parceiro político-pedagógico do professor à medida que os saberes e os conhecimentos interagem, tendo em vista que os seus objetivos consistem na melhoria da aprendizagem e do desempenho escolar.

Os depoimentos de professores (as) participantes desse estudo são bastante ilustrativos dessa realidade, pois quando perguntados sobre como avaliam a atuação do pedagogo na função supervisora de sua instituição, percebe-se a confirmação de que a visão de um pedagogosupervisor que fiscaliza e controla está sendo superada, conforme se pode observar em alguns destes depoimentos:

Uma atuação compartilhada e de assessoramento, pois os mesmos demonstram ser profissionais muito responsáveis e dedicados. Eles buscam mecanismos para melhor atender o professor e o aluno. São compreensíveis e flexíveis. (PROFESSOR 1 - Área: Geografia)

Hoje vejo que o pedagogo não passa mais uma imagem de alguém que vai fiscalizar e punir. Ele na verdade, compartilha e assessora os professores e toda equipe envolvida no processo de ensino aprendizagem. Isso fica bem claro de ser justificado no IFAP porque as decisões (sejam elas acertadas ou não) são tomadas em conjunto. (PROFESSOR 7 - Área: Alimento)

\section{COMPETÊNCIAS E DESAFIOS DO PEDAGOGO NA FUNÇÃO SUPERVISORA}

Considerando o objetivo deste estudo, convém destacar que o pedagogo do século XXI, diferentemente do anterior, precisa perceber que vive-se hoje em um momento compreendido por muitos estudiosos como pós-moderno, marcado por constantes transformações que ocorrem em todo o mundo com grande velocidade, além de ser enfatizada de forma acentuada o fenômeno da globalização em variadas temáticas.

O momento é então de reestruturação de paradigmas, tanto na perspectiva sociocultural como na perspectiva do mundo do trabalho. E em meio a essa configuração, surgem novas demandas de formação e desafios para o pedagogo, que diante das exigências do mercado precisa ser mais competente, desenvolver novas formas de aprender, novas competências e novas formas de realizar o trabalho pedagógico.

Nesse sentido, ao pedagogo que desenvolve um trabalho complexo na escola, compete enquanto supervisor, refletir permanentemente sobre o fazer pedagógico da escola, assumindo, para tanto, como educador, a dimensão política de sua função.

Conforme afirma Medina (2002, p.46): 
O supervisor abdica de exercer poder e controle sobre o trabalho do professor e assume uma posição de problematizador do desempenho docente, isto é, assume com o professor uma atitude de indagar, comparar, responder, opinar, duvidar, questionar, apreciar e desnudar situações de ensino, em geral, e, em especial, as da classe regida pelo professor.

Esta mudança na postura do supervisor demanda outras atribuições, fazendo com que os professores busquem no trabalho do pedagogo-supervisor uma ação renovada, compartilhada, de apoio, de orientação, tendo em vista qualificar sua ação pedagógica no contexto da escola.

Mas na realidade atual, quais motivos de fato levam os professores a recorrerem ao pedagogo-supervisor e que atividades eles acham que o pedagogo deve desenvolver para ajudálos? Ao fazer essa pergunta aos professores da Instituição de Educação Profissional pesquisada, foram apresentadas as seguintes respostas, conforme se pode observar:

Recorro à pedagoga para atualização sobre os eventos da escola, sugestões de dinâmicas em sala de aula, prazos de entrega de provas e outros documentos. Para ajudar o professor acho que o pedagogo deve procurar desenvolver palestras e/ou projetos que objetive melhorar o comportamento dos alunos na instituição; promover momentos de estudos e descontração no ambiente de trabalho (PROFESSOR 3 - Área: Português)

Recorro à pedagoga para dúvidas com relação ao preenchimento dos diários, quanto ao calendário escolar, aos projetos e atividades desenvolvidas na instituição. Para ajudar o professor, acho que o pedagogo deveria realizar acompanhamento mais individualizado, verificando modificações no plano de aula, dentre outros. Mas tal ação no IFAP ainda não é muito possível devido ao número reduzido de pedagogos. (PROFESSOR 4 - Área: Física)

Diante das respostas, pode-se observar que três categorias gerais são contempladas:

1- Aspectos pedagógicos: compreendem atividades relacionadas ao planejamento de aulas, interdisciplinaridade, avaliação do aluno, metodologia/recursos didáticos, alunos com dificuldade de aprendizagem, elaboração e orientação em projetos, turmas e alunos com baixo rendimento;

2- Aspectos operacionais: relacionam-se, por exemplo, com a organização de eventos comemorativos, dúvidas sobre regulamentos, preenchimento de pautas e legislações; e por fim;

3- Aspectos subjetivos: referem-se aos assuntos relativos à indisciplina, à frequência e à motivação dos alunos.

No entanto, a consolidação dos dados coletados demonstrou que a grande maioria dos professores, no dia-a-dia da escola, busca o pedagogo para apoio nos aspectos pedagógicos, seguido dos aspectos subjetivos, pois acreditam que estas sejam as atribuições essenciais do pedagogo, justificando, portanto, sua existência na escola.

A demanda deste profissional no que tange aos aspectos operacionais não foi tão destacada, comprovando a ideia de Pimenta quando afirma que o pedagogo contribui com os professores no trabalho de organizar diferentes modos de ensinar os diferentes conteúdos, ter conhecimento sobre os processos de aprendizagem, enfim, tarefas e saberes pedagógicos fundamentais à prática docente (PIMENTA, 2002). 
Em outras palavras, o trabalho do pedagogo na função supervisora está relacionado principalmente ao Planejamento escolar, à avaliação e formação continuada, sendo o pedagogo um articulador que precisa estar sintonizado com a gestão do trabalho pedagógico desenvolvendo ações de parceria, articulação, informação, colaboração, orientação e diálogo.

Isso implica afirmar que o pedagogo enquanto supervisor tem papel fundamental também na formação de professores no próprio local de trabalho, uma vez que está à frente de alguns "espaços na escola que se, devidamente organizados, podem colaborar para a formação continuada dos professores. São eles: a reuniões pedagógicas, os conselhos de classe, o conselho de escola, o processo de elaboração do PPP, a hora-atividade" (ALMEIDA; SOARES, 2010, p.61).

Na verdade, pode-se afirmar que há uma oportunidade histórica se construindo em relação ao trabalho do gestor pedagógico, uma vez que permite criar condições e/ou potencializar e dinamizar experiências com os professores, o que muitas vezes se observa ocorrendo sem integração, por isso seu papel é fundamental na formação de professores, ou seja, no suporte à preparação, compreensão e análise do trabalho e prática docente à luz de um referencial teóricometodológico que lhe permita pensar na construção e fortalecimento de uma escola de qualidade.

Na concepção de TARDIF (2002, p.38-39),

[...] os próprios professores, no exercício de suas funções e na prática de sua profissão, desenvolvem saberes específicos, baseados em seu trabalho cotidiano e no conhecimento do seu meio. Esses saberes brotam da experiência e são por ela validados. Eles incorporam-se à experiência individual e coletiva sob a forma de habitus e de habilidades, de saber-fazer e de saber-ser. (TARDIF, 2002, p. 3839).

Então, ainda no entendimento de Tardif (2012), o saber docente é um saber plural que se origina da formação profissional (saberes construídos pelas instituições de formação de professores); de saberes disciplinares (que surgem da tradição cultural); curriculares (programas escolares) e experienciais (os que emergem do trabalho cotidiano), o que exige do professor capacidade de dominar, integrar e mobilizar tais saberes enquanto condição para a sua prática.

Assim, compreende-se que o professor para além da formação inicial, deve contar com a formação continuada e a formação em serviço como ferramentas de extrema importância para o seu aperfeiçoamento, visto que estes espaços proporcionam oportunidade de estudar/pesquisar/avaliar as práticas educativas, trocar experiências, desenvolver novas técnicas e fortalecer a equipe docente enquanto coletivo.

Nesta perspectiva, compreendendo o papel do pedagogo como articulador entre as questões administrativas e didático-pedagógicas, ou seja, como executor de tarefas e saberes pedagógicos fundamentais à prática docente, cabe ressaltar que os saberes do pedagogo, segundo Pimenta (2002, p. 177) não são superiores nem inferiores aos dos professores, "[...] ele possui uma especificidade que completa e amplia a especificidade de cada professor (especialista numa área), da mesma forma que completa e amplia sua própria especificidade, a partir de cada área".

Diante desse papel de articulador incumbido ao pedagogo, na ótica do professor como fica estabelecida a sua relação com este profissional e na ótica do pedagogo, como se dá a relação com os professores e a gestão? Na instituição pesquisada apresenta-se a seguinte realidade: 
ÓTICA DO PROFESSOR: relação com o pedagogo

De maneira harmônica. Eu os tenho como parceiros para ajudar no bom andamento das atividades educacionais na instituição (PROFESSOR 2 - Área: Química).

Em alguns casos, ocorrem conflitos de opiniões. (PROFESSOR 6 - Área: Mineração)

ÓTICA DO PEDAGOGO: relação com os professores e gestores

Existe uma relação de parceria, desenvolvida a partir de um trabalho coletivo e solidário. Mas também ainda existe uma relação de rejeição por parte de alguns docentes, relacionada à origem histórica do supervisor escolar (...). A relação dos pedagogos com a Gestão é também de parceria e diálogo aberto. Gostaria de ressaltar que essa relação é bem alicerçada, pois a Direção de Ensino é ocupada por uma profissional formada em Pedagogia, o que proporciona uma gestão com os olhos no pedagógico. (PEDAGOGA 1 - COORDENADORA PEDAGÓGICA).

A relação entre professores e pedagogos sempre são um pouco conflituosas, mas no IFAP à medida que o trabalho pedagógico vai se desenvolvendo, as resistências vão diminuindo e hoje temos uma relação bastante harmônica, de diálogo e respeito mútuo. A direção sempre se mostra acessível e aberta ao diálogo (...). (PEDAGOGA 3).

\subsection{A atuação do pedagogo na Educação Profissional e seus desafios.}

Desde 2008, observa-se a expansão da Rede Federal de Educação Profissional, Científica e Tecnológica (RFEPCT) em todo país, o que oferece terreno propício para discutir mais profundamente aspectos desta modalidade de ensino. Especificamente, neste artigo busca-se identificar quais os desafios postos ao pedagogo no cotidiano de uma instituição de educação profissional, apesar de saber que o papel do pedagogo na educação profissional ainda é pouco debatido tanto na literatura da área quanto nas discussões nacionais a respeito da identidade deste profissional.

Os Institutos Federais, integrantes da RFEPCT e criados pela Lei $n^{\circ} 11.892 / 2008$, são instituições de educação superior, básica e profissional, pluricurriculares e multicampi, especializados na oferta de educação profissional e tecnológica nas diferentes modalidades de ensino, com base na conjugação de conhecimentos técnicos e tecnológicos com as suas práticas pedagógicas.

Percebe-se que os IFs caracterizam-se como instituições com o campo de atuação muito amplo, que vai desde a educação básica ao nível superior. E como Instituição de Ensino não poderia faltar a figura do pedagogo.

Nos Institutos Federais, conforme atribuições descritas pelo Ministério da Educação - MEC - por meio do Ofício Circular n 15/2005 CGGP/SAA/SE/MEC e editais próprios, o pedagogo pode desenvolver as atividades de supervisão pedagógica; orientação educacional; planejamento de atividades pedagógicas e educacionais; controle e registros acadêmicos; definição de políticas de educação para a RFEPCT; assessoramento em relação à legislação educacional; organização e desenvolvimento curricular; coordenação de processos seletivos; relação escola, comunidade 
escolar e mundo do trabalho; gestão do projeto político-pedagógico; formação continuada de professores; gestão da inovação tecnológica, entre outras.

No Instituto Federal do Amapá - Campus Macapá, espaço da investigação, quando questionados sobre quais tipos de atividades desenvolvem nesta instituição, as respostas dos pedagogos se encaixam em um pouco de cada ação que foi mencionada acima.

Assim, diante desse vasto campo de atuação dentro de uma instituição de educação profissional, surgem questionamentos e a necessidade de delinear quais os saberes necessários a serem incluídos na formação deste profissional que lhe dê condições de responder efetivamente às tarefas e desafios que foram citados como de sua competência dentro dos processos educativos.

Isso leva a seguinte situação: a formação no Curso de Pedagogia proporciona conhecimentos suficientes para atuação na educação profissional? Essa atuação do pedagogo em Instituições de Educação Profissional é diferente da atuação em uma Instituição comum de educação básica? As pedagogas que atuam no IFAP com educação profissional têm o seguinte posicionamento:

O curso não proporciona conhecimento suficiente, mas esse conhecimento específico para atuar na educação profissional pode ser adquirido através de complementação e pós-graduação. A atuação na educação profissional abrange a educação básica e vai além dela, pois precisa-se ter embasamento teórico-prático do ensino profissionalizante, conhecer as leis e diretrizes da educação profissional, os cursos ofertados de acordo com as exigências e demandas do mercado de trabalho (...).(PEDAGOGA 1 - COORDENADORA PEDAGÓGICA).

Não proporciona conhecimento suficiente, pois o processo educativo é muito complexo, exigindo que a atuação do pedagogo seja além do campo teórico, demandando também um conhecimento específico voltado para a formação profissional. Considero a nossa atuação seja parcialmente semelhante em uma instituição comum de educação básica, no que se refere ao planejamento, organização, implementação e articulação de projetos pedagógicos, orientação, entre outros. Mas, necessita-se investir numa formação teórica/metodológica voltada para a educação profissional, que dê condições ao pedagogo de responder efetivamente aos desafios e trabalhos que fazem parte de seu fazer pedagógico. (PEDAGOGA 2).

Pelos relatos acima, pode-se perceber que os estudos no Curso de Pedagogia, proporcionam uma formação ampla dos aspectos educativos, pedagógicos, sociais e psicológicos, não se adentrando especificamente no campo da educação profissional. O que não está incorreto, pois a pedagogia é uma ciência da educação, que se distingue das outras ciências, justamente por estudar o fenômeno educativo em sua totalidade.

Assim, o pedagogo disposto a atuar em educação profissional, não necessita ter conhecimento técnico especifico, dentre as diversas áreas abrangentes do mercado de trabalho. Para destacar-se em sua função, é preciso antes de tudo, conhecer sobre o processo com o qual irá lidar, ou seja, a educação profissional. Por isso, deve buscar aprofundar seus estudos para que possa exercer com qualidade suas competências e contribuir no processo ensino-aprendizagem no campo da educação profissional. 
Segundo as reflexões de Pimenta $(2002$, p.188) no que se refere à formação do pedagogo, são requisitos básicos:

[...] uma sólida formação de história e filosofia da educação que permita-lhe compreender os problemas atuais da educação e a educação como prática social articulada às demais.Compreender a escola como instância fundamental para a emancipação das camadas populares. Mais do que compreender, espera-se que o pedagogo apresente soluções competentes. Para isso, toda a parte de instrumentação se faz necessária. Pode-se destacar a necessidade do conhecimento do processo de aprendizagem como fundamental, de modo a que se saiba articular o lógico (dos conhecimentos científicos, técnicos) com o psicológico (do ser que aprende).

Dessa forma, o pedagogo na educação profissional, além de ter o desafio de buscar qualificação para atender melhor às expectativas desse campo de atuação, tem o desafio de (conforme colocam as pedagogas da Instituição pesquisada): buscar superar a aversão que sofrem por parte de alguns professores; saber lidar com as faltas dos professores e incentivar que ele tenha compromisso com a instituição, fazer superar a visão tecnicista e fragmentada do trabalho pedagógico, resgatando-o em sua totalidade; trabalhar com a interdisciplinaridade que exige muito tempo de planejamento, o que é difícil hoje devido ao grande acúmulo de projetos em que os educadores precisam lidar, superar a ausência da família na escola; criar e fortalecer espaços de participação e vivências inclusivas.

\section{CONSIDERAÇÕES FINAIS}

A pesquisa aponta que os desafios e problemáticas vivenciadas pelo pedagogo na função supervisora de uma Instituição de Educação Profissional, são semelhantes aos de outras instituições de ensino da rede pública. A diferença está no fato dele ter que aprofundar seus estudos para que possa exercer com qualidade suas competências e contribuir no processo ensinoaprendizagem no campo da educação profissional.

A investigação teórica sobre a relação do corpo docente com os pedagogos mostra que é histórica a presença ainda de uma relação pouco harmônica. No entanto, a pesquisa de campo realizada revelou que o pedagogo tem conquistado espaço aos poucos, construindo uma relação de mediador nas relações pedagógicas e se responsabilizando com o professor, sem querer determinar o que ele tem que fazer, mas orientar. Ou seja, através da conquista para o diálogo, o resultado tem sido melhorias nessa relação e um trabalho mais tranquilo, pautado em decisões coletivas.

A pesquisa aponta ainda, como fundamental e necessária a formação continuada, tanto dos docentes quanto do pedagogo, bem como a articulação dos saberes desses profissionais para a consolidação de práticas educativas. Segundo Tardif (2002), esses saberes são os da formação profissional, tradição pedagógica, experiencial e da ação pedagógica.

Esta formação poderia ser realizada por meio da pesquisa, em cursos de pós-graduação, e também ao longo do próprio exercício profissional, em espaços intencionalizados e sistematizados de formação em serviço, articulando os saberes do fazer pedagógico com aqueles acumulados ao longo da vida. 


\section{REFERÊNCIAS BIBLIOGRÁFICAS}

1. ALMEIDA, Claudia Mara de; SOARES, Kátia Cristina Dambiski. Pedagogo Escolar: as funções supervisora e orientadora. Curitiba: Ibpex, 2010.

2. BRASIL. Lei no 11.892, de 29 de dezembro de 2008. Institui a Rede Federal de Educação Profissional, Científica e Tecnológica, cria os Institutos Federais de Educação, Ciência e Tecnologia, e dá outras providências.

3. _. Ministério da Educação. Encaminha a descrição dos cargos técnico-administrativos em educação, que foram autorizados pelo Ministério de Planejamento, Orçamento e Gestão para concurso público. Ofício Circular no 015/2005/CGGP/SAA/SE/MEC, de 28 de novembro de 2005.

4. . Ministério da Educação. Conselho Nacional de Educação. Conselho Pleno. Resolução

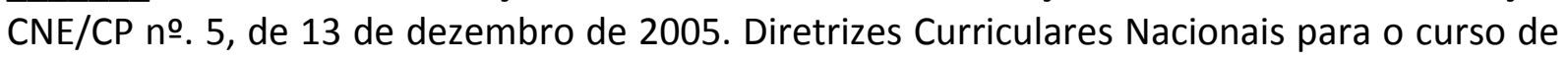
Pedagogia. Disponível em: <http://portal.mec.gov.br/cne>. Acesso em: 07 jan. 2012.

5. FALCÃO FILHO, J.M. Uma supervisão compartilhada: a relação professor/supervisor. Minas Gerais: Fundação AMAE para Educação e Cultura, Mai. 1994.

6. LIBÂNEO, José Carlos. Pedagogia e Pedagogos, para quê? 9. ed. - São Paulo, Cortez, 2007.

7. MEDINA, Antonia da S. Supervisão escolar: da ação exercida à ação repensada. Porto Alegre: AGE, 2002.

8. PIMENTA. Selma Garrido. O pedagogo na escola pública. São Paulo: Loyola, 2002.

9. SAVIANI, Demerval. A Pedagogia no Brasil: história e teoria. Campinas, SP: Autores Associados, 2008.

10. TARDIF, Maurice. Saberes docentes e formação pr 